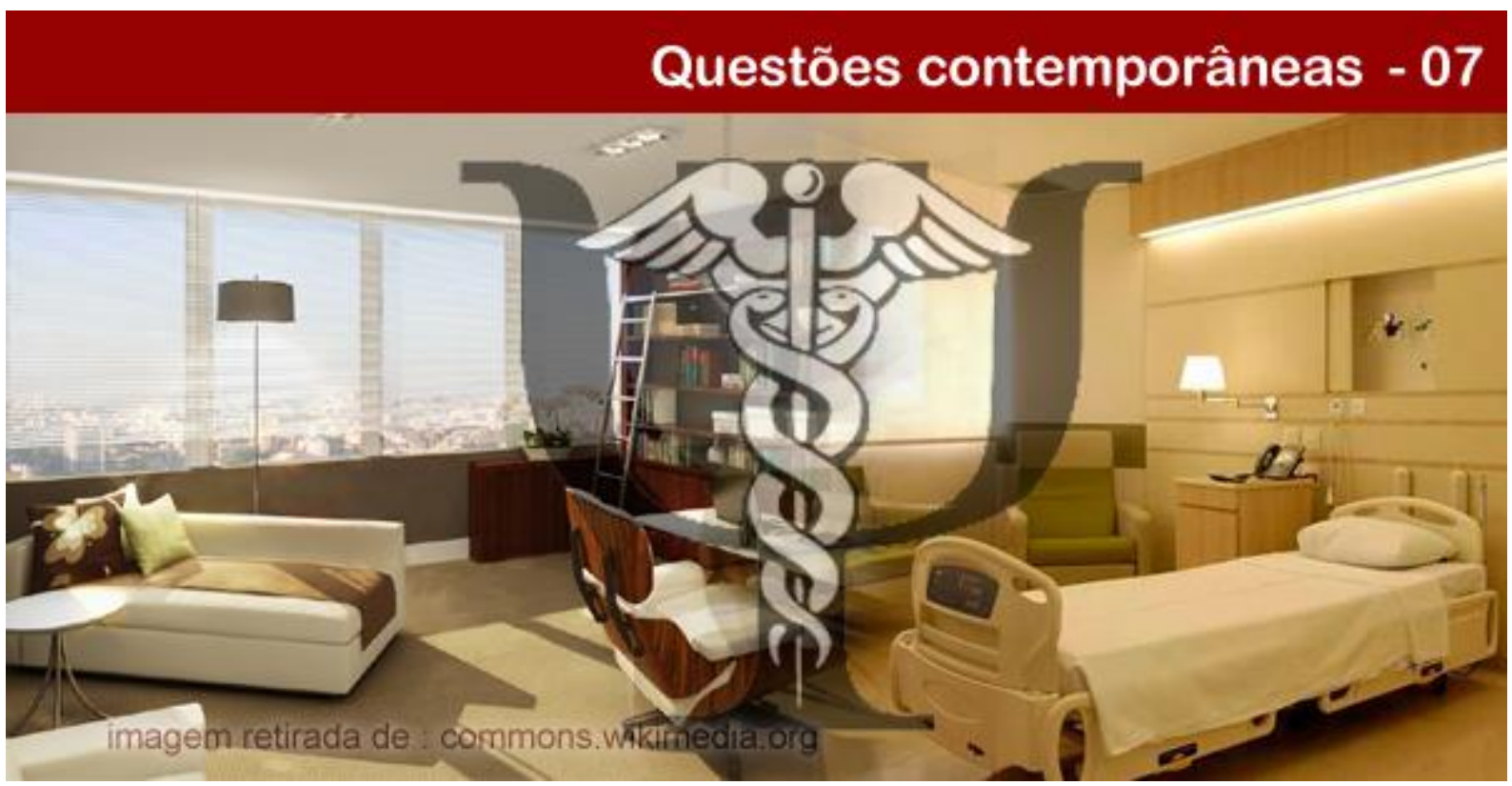

\title{
INQUIETAÇÕES E CONSTRUÇÕES: UM TRABALHO NO HOSPITAL GERAL À LUZ DA PSICANÁLISE
}

\begin{abstract}
Nathalie Pavese
Psicóloga, graduada pela Universidade Federal do Paraná (UFPR), residente no Programa de Residência Integrada Multiprofissional em Atenção Hospitalar no Hospital de Clínicas da UFPR. E-mail:
\end{abstract} nathalie.pavese@gmail.com.

\section{Tiene Guimarães}

Psicóloga, graduada pela Universidade Federal do Paraná (UFPR), residente do Programa da Saúde da Criança e do Adolescente no Hospital de Clínicas da UFPR. E-mail: tiene.guimarães1@gmail.com

Resumo: Mediante a atuação da psicologia, segundo orientação psicanalítica, em uma residência multiprofissional no hospital geral, encontram-se diversos impasses e limitações que demonstraram a necessidade de desenvolver este estudo. Desse modo, permanecem as questões: existe espaço para a psicanálise em uma instituição na qual há a supremacia do orgânico? Ela se faz possível dentro de um programa de residência que envolve profissionais de diversas categorias da área da saúde? Tais dúvidas, advindas da atuação, carecem de tentativas de respostas, afinal, as dificuldades encontradas não são impeditivas para o trabalho. Elas enaltecem o que é próprio da psicanálise, perpassadas por questionamentos provindos de inquietações clínicas. Quando a equipe se depara com contradições, quando o paciente não "adere ao tratamento" médico, surge o pedido de que se exclua isso a fim de apaziguar o sujeito. Com base nos textos freudianos e contemporâneos foi possível desenvolver diversas reflexões, dentre elas: as visitas médicas; a supervisão em uma instituição; a pesquisa em psicanálise; a dificuldade em se preservar o sigilo e a ausência do setting analítico; e, sobretudo, o espaço que a psicanálise ocupa em um local onde a cura de doenças orgânicas é priorizada frente à subjetividade. Ao lidar com o inconsciente, com as angústias, com o sofrimento e com o que a internação pode provocar na subjetividade, percebe-se que a inserção da psicanálise, apesar das dificuldades, é essencial nesta instituição.

Palavras-chave: Psicanálise. Hospital. Residência multiprofissional. Subjetividade.

\section{RESTLESSNESS AND CONSIDERATIONS: A STUDY ON THE GENERAL HOSPITAL ENLIGHTENED BY PSYCHOANALYSIS}

\section{POLÊM!CA | Revista Elerơnica da Uej}




\begin{abstract}
The performance as a psychologist, with psychoanalysis orientation, in a multifunctional residency at a general hospital, found many limitations and issues, which makes necessary the development of this study. Thereby, some questions are made: Is there space for psychoanalysis in an institution, which has organic supremacy? Psychoanalysis is possible inside a residency program involving professionals in different health categories? Such doubts, created during performance, struggle to find an answer; after all, these issues do not prevent the work to happen. They magnify what is characteristic of psychoanalysis, which is questioning work related issues. When a team faces contradictions, a patient do not "accept the medical treatment", a request is made to erase this to pacify the subject. In accordance with Freud and contemporary texts it was possible to create several reflections, such as: doctor visits; supervisor in an institution; psychoanalysis research; the difficulty to respect confidentiality and absence of analytical setting; and most of all, the space that psychoanalysis belongs in a place where cure of organic disease is prioritize in front of subjectivity. Dealing with unconscious, anguish, suffering and the meaning of admission to a hospital can cause subjectivity, it is possible to notice that psychoanalysis, even with difficulties, is essential in this institution.
\end{abstract}

Key Words: Psychoanalysis. Hospital. Multifunctional Residency. Subjectivity.

Este trabalho se trata da formalização de diversas questões provindas da experiência prática das autoras especificamente na residência multiprofissional em atenção hospitalar no Hospital de Clínicas da Universidade Federal do Paraná (HC-UFPR). A partir de uma atuação de orientação psicanalítica no hospital foram encontrados diversos impasses e limitações que nos convocaram a desenvolver este estudo de forma a nos questionarmos se existe um espaço para a psicanálise em uma instituição na qual há a supremacia do orgânico.

A residência multiprofissional tem como foco principal a atenção hospitalar e engloba diversas profissões da área da saúde, tendo como objetivo a formação desses profissionais dentro dos princípios do SUS. Estamos em um hospital escola, dentro de um programa com perfil de pós-graduação. Trabalhamos 60 horas semanais, divididas entre assistência (75\%) e estudos - TCR (Trabalho de Conclusão de Residência), aulas e leituras - (25\%).

Durante todo o percurso apostamos que as mais diversas dúvidas advindas da atuação carecem de tentativas de respostas, e que as dificuldades encontradas não são impeditivas para o trabalho. Elas enaltecem o que é próprio da psicanálise, perpassadas por questionamentos provindos de inquietações clínicas. Ao iniciarmos o trabalho no hospital percebemos o fato de que a instituição é da ordem do acalmar, convencer o paciente, eliminar a angústia. Somos chamados pela equipe quando esta se depara com contradições. E, quando a subjetividade atrapalha o andamento do tratamento médico, o pedido é que isto seja excluído. Assim como afirma Clavreul (1983), algo da relação médico-paciente escapa, porque estes fenômenos psíquicos não são considerados e, por isso, são descartados. Portanto, o que fazemos em nosso trabalho vai à contramão disso que seria a psicologia hospitalar, que visa se inserir nessa lógica e auxiliar na adaptação do internamento.

\title{
POLÊM!CA | Revista Eetrônica da veri
}


Em contraponto a isso, abrimos um espaço para que o sujeito fale e não se cale. Fazemos entrevistas preliminares, oferecemos uma escuta, possibilitamos que o paciente tenha a liberdade de falar sobre o que quiser, sem nenhum tema determinado. É importante ressaltar que esse espaço oferecido também pode ser negado, ou seja, o paciente tem autonomia para dizer se quer ou não o atendimento, diferente dos outros profissionais que, independente da vontade do paciente, precisam realizar os atendimentos. Ao acreditar que a psicanálise tem como ferramenta de trabalho a palavra, faremos intervenções no sentido de abrir esse discurso. Assim, somos remetidos à história do paciente e não ficamos focados na internação e na doença se isso não for trazido por ele. Segundo Figueiredo (1997) "o pacto analítico é um pacto da fala. A psicanálise é uma clínica da fala. Fazer falar é uma condição da escuta e é pela escuta que a fala se constitui". Para a lógica médica, somente é possível a execução da considerada 'boa medicina' quando há uma mútua exclusão: do que emerge do paciente para além das questões orgânicas e do que é despertado no médico para além das questões profissionais. Sendo assim, o que é próprio da subjetividade de ambos é deixado à margem (CLAVREUL, 1983). A relação que é própria entre médico e paciente, de acordo com Foulcault (1980), não é interessante para a medicina, afinal, o campo desta metodologia é delimitado e, quando se coloca em pauta as questões do inconsciente, há algo que sempre escapa.

Diante de todo esse contexto e a partir de várias discussões e dúvidas que foram surgindo ao longo desse ano de residência, ressaltamos alguns pontos que julgamos ser de fundamental importância para o nosso trabalho e que nos colocaram - e ainda colocam - em movimento. São questões com as quais nos deparamos diariamente e que nos fazem pensar constantemente sobre o trabalho com a psicanálise no hospital.

\section{Visita médica}

Participamos das visitas médicas que ocorrem diariamente em cada unidade. Pela dificuldade de entendimento da equipe da função de um psicólogo nesse espaço, alguns impasses foram encontrados. Primeiro que em algumas unidades apenas médicos e enfermeiros faziam parte da equipe e participavam da rotina, aparecendo outro profissional apenas quando solicitado. Inserir a rotina da psicologia não foi tarefa fácil e, por vezes, nos interrogamos se realmente tal participação nas visitas era de fato necessária. Com o dia-a-dia

\section{POLÊM!CA | Revista Eletronica da ver}


observamos o quanto participar da visita médica e perceber a relação entre medico x paciente $\mathrm{x}$ doença era fundamental. Neste momento, quando uma notícia é dada, um diagnóstico é feito ou quando se observa a interação entre paciente e acompanhante, é possível notar as dificuldades, o sofrimento e a angústia sentidos e, a partir disso, perceber quem precisa de atendimento.

Em contraponto, pela dificuldade dos outros profissionais entenderem a lógica e a forma de trabalho com a psicanálise, a questão que surge é da falta de uma visita que seja literalmente multiprofissional. A médica, apesar dos pontos positivos, ainda é muito limitada apenas à visão organicista, da detecção dos sintomas, da determinação dos medicamentos e, por fim, da espera da cura.

Como as visitas ocorrem nos leitos, ao redor do paciente em questão, a avaliação médica, de acordo com Schneider (2013), dispensa a presença do paciente, afinal, apenas o que importa são os dados do corpo. É este que se apresenta com uma qualidade de máquina e é nessa lógica que o discurso médico se encaixa, nessa separação do corpo em detrimento daquele que se expressa. O paciente é excluído, sendo analisado somente esses fatores, sem levar em consideração o sujeito que está ali, que ouve, que entende e que tem dúvidas com relação ao que é discutido e na maioria das vezes é ignorado por aqueles que estão no quarto. O psiquismo é tratado pela ordem médica como algo que eclode inesperadamente e de maneira indevida, em circunstâncias que acabam por promover um mal-estar, provocando um transtorno a todos que se incluem nessa lógica (MATTOS, 2008). Assim, somente quando o paciente traz 'problemas' que o psicólogo passa a fazer parte da equipe, como aquele que 'dá um jeito' naquilo que foge do entendimento deles, foge do comum e faz uma ruptura no bom andamento do trabalho. "No que tange ao doente, a preferência é que permaneça silencioso" (SCHNEIDER, 2013). Nesse ponto, ainda há algo que permanece em discussão.

\section{Supervisão}

Com relação à supervisão destacamos diversas considerações. Primeiro da dificuldade da escolha. Quando se entra na residência a escolha é feita pelo programa e pela linha teórica, não se escolhe o supervisor e muitas vezes os que ingressam nem conhecem o profissional que dará a supervisão, sendo que, dependendo do setor, tem um supervisor para cada local. Pela lógica da psicanálise, entendemos a importância da escolha e, mais do que isso, o

\section{POLÊM!CA | Revista Eletronica da Ueij}


pagamento feito a esse supervisor. Como um dos principais pontos da residência é a exigência de que se tenha um supervisor o tempo todo com o residente, a fim de promover um melhor aprendizado, e a supervisão não pode ser cobrada, esse mecanismo acaba perdendo o sentido ou se tornando apenas mais uma 'discussão dos casos' do que de fato uma supervisão. Sendo, portanto, outro ponto de dificuldade.

Um último ponto que ressaltamos é a diversidade de papéis assumidos pelo supervisor. Ao mesmo tempo em que ele ocupa esse lugar, muitas vezes ele também desempenha o papel de coordenador e de orientador. Sendo assim, os limites entre um e outro acabam se misturando e dificultando ainda mais o trabalho. Aquele que dá a supervisão também é que faz a cobrança da parte burocrática e orienta as questões do TCR, não conseguindo manter um lugar onde apenas uma das funções esteja bem delimitada.

A supervisão, para aqueles que trabalham seguindo a lógica psicanalítica, é o local no qual há um encontro entre o universal da teoria e o particular da clínica (SCHNEIDER, 2013). Desse modo, é fundamental que ela ocorra em um contexto no qual o controle, a inspeção ou a garantia de um 'andar na linha' não interfiram no trabalho, corroborando para o que Schneider (2013) aponta como um espaço que permita ao supervisionante encontrar considerações a partir de sua própria experiência, a fim de refletir sobre seus atos e suas consequências.

\section{Trabalho de conclusão de residência (TCR)}

Com relação ao TCR, ao final do período de residência, este deve ser submetido a uma revista científica a fim de ser publicado. É o último requisito para que o certificado seja emitido. Entretanto, a lógica que foi estabelecida para a execução desse trabalho nos faz sempre interrogar como é feita a pesquisa em psicanálise. Acreditamos que para ter um tema de pesquisa é necessário que algo seja questionado e que essa questão surja a partir da experiência clínica, considerando que, ao inverter a ordem, a escuta acaba sendo muito limitada e até contaminada pelos mais diversos fatores. Segundo Mezan (1993) a pesquisa em psicanálise surge precisamente da insatisfação com o já sabido; realizada a pesquisa podemos retornar a clínica instrumentalizados, mas sem nenhuma dúvida de que novas questões surgirão.

\section{POLÊM!CA | Revista Eletronica da Uej}


A exigência dos coordenadores dos programas de residência é que o tema seja escolhido logo no primeiro semestre, no qual um projeto seja estruturado e passe a ser produzido o mais breve possível, o que, dentro da lógica psicanalítica, consideramos ser impossível. Outra dificuldade encontrada é o fato de, ao estarmos inseridos em um hospital, a principal exigência em uma pesquisa é o encaminhamento desta ao comitê de ética, para que forneça uma autorização para a aplicação dos questionários, constando o termo de consentimento livre e esclarecido. E, mais ainda, para que esse processo ocorra dentro de um período possível para a aplicação da pesquisa é necessário que tudo esteja pronto, pelo menos, ao final do primeiro ano. Ao estudar a psicanálise e ao optar por fazer uma pesquisa nessa linha, consideramos impeditivo para o trabalho a exigência de um termo de consentimento. Ao ser assinado pelo paciente, isso interfere diretamente na transferência estabelecida e pode acarretar consequências para o atendimento, se é que algo da confiança possa ser estabelecida no momento em que o paciente sabe o que está sendo estudado e qual o objetivo do trabalho. Freud, em seu texto Dois verbetes de enciclopédia, diz:

Psicanálise é o nome de (1) um procedimento para a investigação de processos mentais que são quase inacessíveis por qualquer outro modo, (2) um método (baseado nessa investigação) para o tratamento de distúrbios neuróticos e (3) uma coleção de informações psicológicas obtidas ao longo dessas linhas, e que gradualmente se acumula numa nova disciplina científica. (FREUD, p. 253, 1923).

Dessa forma, faz parte também do nosso trabalho fazer as pessoas entenderem que existe uma lógica diferente em nossa prática, já que trabalhamos com o inconsciente, e que não é possível seguir as regras impostas para isso, com termos e afins.

\section{Prontuário, sigilo e equipe multiprofissional}

Como regra do hospital, para bom entendimento e interação entre equipe/setores e por questões de faturamento, todo profissional deve registrar seus atendimentos tanto no sistema quanto no prontuário, do necessário diálogo com toda a equipe, bem como a organização de estudos de caso para serem apresentados. Diante disso, o que sempre é um ponto amplamente questionado por todo o serviço de psicologia é: o que escrever no prontuário? Como escrever algo do seu atendimento que seja importante para os outros profissionais sem ferir a ética do sigilo, na qual o paciente confia para nós os mais diversos sofrimentos e angústias que o acometem, ou mesmo algo que seja notado por nós ou que envolve diretamente ou

\section{POLÊM!CA | Revista Eletronica da Uej}


indiretamente outro profissional da equipe? Como fazer isso sem ao mesmo tempo estar expondo o paciente? E como transmitir uma informação importante, que pode ser decisiva para o tratamento, de uma forma que seja entendida sem detalhes que possam comprometer todo o trabalho? Uns defendem que apenas escrever "atendimento realizado" é o suficiente. Outros que algo de relevante deve ser informado, senão não faria sentido tal anotação. Nesse sentido e levando em consideração também que o prontuário é público - qualquer profissional e o próprio paciente podem ter acesso a qualquer momento a todas as informações -, é mais um ponto a ser questionado recorrentemente.

\section{Dificuldades com outros profissionais, outras pessoas/pacientes na enfermaria}

Outro ponto que consideramos importante debater é a forma como os atendimentos são feitos. Os nossos atendimentos prioritariamente são realizados nos leitos, o que já pressupõe um setting bem diferente do usual para uma análise, com exceção de alguns casos que acreditamos ser necessário um atendimento em um ambiente mais privado, ou mesmo quando o paciente está autorizado a sair do quarto. Assim como já foi falado, temos autonomia para saber quem atender, se o paciente ou o acompanhante, ou o dois, vai do caso a caso. Como a psicologia é um serviço relativamente novo no hospital e, como já destacamos, em muitas unidades é a primeira vez que o psicólogo é inserido na equipe, muitos profissionais não entendem como trabalhamos. Ao atender no leito sabemos que há uma rotina da enfermagem e da medicina que, em determinados momentos não podem ser adiadas, como um horário de medicação, um exame, etc. Assim como sabemos que seria bom que o nosso atendimento ocorresse com o mínimo de interrupções possíveis. O que notamos é, de fato, uma falta de conhecimento e, algumas vezes, uma falta de respeito para com o nosso trabalho. Como os médicos não gostam de ser interrompidos, os fisioterapeutas não podem abandonar um procedimento, nós também não podemos ter interrupções e isso não é entendido por muitos da equipe. Os outros profissionais que desconhecem a forma como trabalhamos demonstram que o atendimento com o psicólogo não passa de uma "conversa", interrompendo pelos mais diversos motivos desnecessários, ou mesmo interferindo com opiniões pessoais, com o intuito de ajudar ou de apenas participar da conversa. Isso é muito frequente e uma das maiores dificuldades encontradas. Por isso, nos é clara a importância de ter definido e sustentado teoricamente que escuta é essa que dispomos ao paciente. Só é

\section{POLÊM!CA | Revista Eletronica da vej}


possível defender um modo de trabalho que difere de toda a lógica assumida pela instituição quando temos bem definido e com base em argumentos sólidos como de fato funciona nosso trabalho. Trabalho esse que deve ser questionado diariamente, com cada atendimento e com cada paciente, levando sempre em consideração o que é próprio da singularidade dessa construção.

Outro problema encontrado é, em algumas unidades, a colocação de vários pacientes no mesmo quarto. $\mathrm{O}$ que por muitas vezes atrapalha e causa desconforto tanto em quem está atendendo quanto em quem está sendo atendido é a interrupção do atendimento pelo paciente que está na cama ao lado, por curiosidade, por interesse pelo que o outro está falando e até para compartilhar suas experiências. E ainda, o que recorrentemente acontece é um impasse no qual mais de um paciente que estão sendo atendidos ficam no mesmo quarto, tendo contato um com o outro e até mesmo perguntando e trocando informações entre si sobre os próprios atendimentos. Quando isso ocorre há uma dificuldade tanto no manejo quanto no próprio desenrolar dos atendimentos. Com afirma Schneider (2013), há nesse contexto a necessidade de um maior rigor no trabalho da escuta, já que se parte da premissa de que a oferta cria uma demanda e que infelizmente o ambiente não é o mais apropriado para que tais questões sejam trabalhadas.

Diante de todas essas inquietações, impasses e impossibilidades, alguns mais formulados e outros ainda em curso, uma pergunta acaba por se destacar: existe espaço para o trabalho psicanalítico no hospital geral?

\section{Em uma instituição onde há a supremacia do orgânico existe espaço para a psicanálise?}

Trabalhamos com a psicanálise dentro do Sistema Único de Saúde, em um hospital que recebe todos os tipos de paciente com as mais variadas patologias e que por muito tempo funcionou apenas a partir da lógica médica. Sem dúvida é difícil essa inserção e por vezes nos questionamos se existe um espaço para a psicanálise. Com a residência e com todas as dificuldades encontradas, acreditamos que sim, existe um espaço para a psicanálise na medida em que entramos na contramão dessa lógica, não levando em consideração apenas o corpo do paciente ou sua patologia. Trabalhamos com o sujeito, com o inconsciente, com aquilo que a internação pode provocar, com suas angústias e com aquilo que é próprio de cada um, sem pressupostos, julgamentos ou receitas, a fim de apenas tamponar tudo o que foge da ordem do

\section{POLÊM!CA | Revista Eletronica da Uej}


orgânico. Vamos aqui com Freud, quando em seu texto "Linhas de progresso na terapia analítica” (1919 [1918]) ele afirma a importância da expansão da psicanálise e até coloca como perspectiva para o futuro a criação de instituições para atendimento de grande parte da população, enfatizando que, mesmo com adaptações necessárias, o analista deve manter os princípios psicanalíticos.

Desse modo, destaca-se mais uma vez o que de mais fundamental se sobressai em todo nosso trabalho - o espaço que oferecemos ao paciente, espaço do inconsciente, que emerge e do qual temos provas constantes da existência e da relevância dentro desse contexto. Seguindo essa lógica, com a prática clínica, percebemos que o fato de estar no hospital é algo desestruturador para vários pacientes, por retirá-lo de sua rotina, por estar em um lugar em que só se vai por que algo de errado está acontecendo. O paciente encontra-se mais fragilizado e isso, por si só, pode se apresentar como fator que desencadeia muitas angústias. Aprendemos com isso a lidar com as mais diversas situações e, no atendimento, a ter um manejo mais minucioso, no sentido de entender que o paciente está sofrendo e que se algo é notado como uma contradição, saber qual é o melhor momento para pontuar, sem desestabilizá-lo de forma devastadora. Existe um tempo que esse paciente necessita para de alguma forma compreender e precisamos defender esse tempo perante a equipe e isto não é tarefa a ser imposta, mas construída. E essa construção, do lugar e do espaço da psicanálise, é tarefa constante e o que nos motivou na elaboração desse artigo e nos motiva a seguir diante de todas essas inquietações.

Acreditamos que nos aproximamos, portanto, da conclusão de Moretto (2001): "O que um analista pode num hospital, concluo, não é mais nem menos do que ele pode em qualquer lugar. O que um analista pode fazer se aproxima bastante daquilo que ele deve fazer, daquilo que é sua função".

\section{Referências}

ClaVreul, J. A ordem médica - Poder e impotência do discurso médico. São Paulo: Editora Brasiliense, 1983.

FIGUEIREDO, A.C. Vastas confusões e atendimentos imperfeitos: a clínica psicanalítica no ambulatório público. Rio de Janeiro: Relume-Dumará, 1997.

FREUD, S. (1919). Linhas de progresso da terapia psicanalítica. In:

Freud. Edição standard brasileira. Vol.XVII. Rio de Janeiro: Imago, 1996.

. Obras psicológicas de Sigmund

\section{POLÊM!CA | Revista Eletronica da Uerj}


(1923). Dois verbetes de enciclopédia. Edição standard das obras psicológicas completas de Sigmund Freud. Rio de Janeiro: Imago, 1996, Vol. XVIII, p. 251-274.

FOUCAULT, M. (1980). O nascimento da clínica. 6.ed. Rio de Janeiro: Forense Universitária, 2006.

MATTOS, P.R. Caso Severino e as peculiaridades do trabalho psicanalítico no território médico. 2008

MEZAN, R. Que significa “pesquisa” em psicanálise? In: SILVA, Maria Emília Lino da (Org). Investigação e psicanálise. Campinas: Papiris, 1993, p. $49-89$

MORETTO, M.L.T. O que pode um analista no hospital? $1^{\text {a }}$ Reimpressão. São Paulo: Casa do Psicólogo, 2013.

SCHNEIDER, V. S. Conceitos fundamentais para uma práxis da supervisão: o trabalho de supervisão em psicanálise num hospital geral. 2013. Dissertação.Mestrado Profissional em Psicanálise, Saúde e Sociedade. Universidade Veiga de Almeida, Rio de Janeiro, 2013. Disponível em:

<http://www.uva.br/mestrado/dissertacoes_psicanalise/Venicius_Scott.pdf>. Acesso em: 01 set. 2014.

Recebido em: 15/06/2015.

Aceito em: 02/10/2015. 